TẠP CHÍ KHOA HỌC ĐẠI HỌC TÂN TRÀO

ISSN: $2354-1431$

http://tckh.daihoctantrao.edu.vn/

\title{
Phát triển năng lực sáng tạo cho sinh viên sư phạm
}

$H a ̀$ Mỹ $H a ̣ n h^{a^{*}}$

${ }^{a}$ Trừ̀ng Đại học Tân Trào

*Email: hamyhanhedu@gmail.com

\section{Thông tin bài viết}

Ngày nhận bài:

$17 / 3 / 2018$

Ngày duyệt đăng:

10/9/2018

\section{Tù khoá:}

Phát triển, năng lực, sáng tạo, năng lục sáng tạo, sinh viên su phạm

\section{Tóm tắt}

Nhà giáo là nhân tố quyết định chất lượng giáo dục - đào tạo, muốn nâng cao chất lượng giáo dục trước hết phải nâng cao chất lượng đội ngũ giáo viên và chất lượng đào tạo đội ngũ giáo viên. Vì vậy, sinh viên các trường sư phạm để trở thành người thầy có tính sáng tạo thì trước tiên phải được phát triển năng lực sáng tạo (NLST) khi còn là học sinh, sinh viên. Bài viết đi sâu phân tích NLST là gì? Mục tiêu, nội dung, phương pháp phát triển NLST cho sinh viên sư phạm; Quy trình phát triển NLST cho sinh viên sư phạm.

\section{1. Đặt vấn đề}

Để đáp ứng yêu cầu hội nhập quốc tế, đòi hỏi giáo dục nước ta phải đổi mới mạnh mẽ để nâng cao chất lượng đào tạo, nhằm cung cấp cho nền kinh tế nguồn nhân lực có đủ trình độ và năng lực vận hành nền kinh tế trong mọi lĩnh vực.Điều này cũng có nghĩa là các trường đại học nói chung và đại học sư phạm nói riêng phải từng bước chuyển mình để trở thành nơi phát triển cho người học những năng lực cần thiết. Muốn vậy, sinh viên các trường sư phạm trước khi trở thành người thầy có tính sáng tạo thì họ cần được phát triển năng lực sáng tạo khi còn là học sinh, sinh viên.

Tuy nhiên, thực trạng dạy học theo hướng phát triển năng lực sáng tạo cho sinh viên sư phạm còn nhiều hạn chế. Bài viết đi sâu phân tích năng lực sáng tạo là gì?Mục tiêu, nội dung, phương pháp, quy tình phát triển năng lực sáng tạo cho sinh viên sư phạm.

\section{Lý luận chung về phát triển năng lực sáng tạo của sinh viên sư phạm}

\subsection{Khái niệm năng lục sáng tạo}

2.1.1. Năng lực

Khái niệm năng lực có nguồn gốc tiếng La Tinh “competentia”, có nghĩa là gặp gõ.

Trong Tâm lí học, năng lực được định nghĩa: "Là tổ hợp các thuộc tính độc đáo của cá nhân, phù hợp với nhũng yêu cầu của một hoạt động nhất định, đảm bảo cho hoạt động đó có kết quả” [7, tr.178].

Dưới góc độ TLH có các quan điểm sau:

Theo tác giả Côvaliôv A. G.: "Năng lực là tập hơp hoặc tổng hợp nhũng thuộc tính của cá nhân con người, đáp úng nhũng yêu cầu của hoạt động và đảm bảo cho hoạt động đạt được kết quả cao ”[1, tr.90].

Nguyễn Quang Uẩn - Trần Trọng Thuỷ (2009): Năng lực là tổ hợp nhũng thuộc tính độc đáo của cá nhân, phù hợp với nhũng yêu cầu của hoạt động nhất định, đảm bảo cho hoạt động đó có kết quả [8]. Theo hai tác giả thì những đặc điểm tâm sinh lý cá nhân là những điều kiện chủ quan để hình thành năng lực, năng lực chỉ hình thành trong hoạt động, không có năng lực ngoài hoạt động.

Tất cả các khái niệm năng lực nêu trên được khai thác dưới góc độ TLH, năng lực là thuộc tính tâm lý cá nhân, nó tạo nên sự thành công của cá nhân trong hoạt động nghề nghiệp, hoạt động sống của con người.

Dưới góc độ dạy học tiếp cận năng lục

- Weiner F. E. (2011): Năng lục là nhũng khả năng và kĩ xảo học được hoặc sắn có của cá thể nhằm giải quyết các tình huống xác định, cũng nhu sụ sã̃n sàng về động co; xã hội... và khả năng vận dụng các cách giải quyết vấn đề một cách có trách nhiệm và hiệu quả trong nhũng tình huống linh hoạt...[9]. 
- Bernd Meier, Nguyễn Văn Cường (2011): Năng lưc là khả năng thực hiện có hiệu quả và có trách nhiệm các hành động, giải quyết các nhiệm vụ, vấn đề thuộc các lĩnh vưc nghề nghiệp, xã hội hay cá nhân trong nhũng tình huống khác nhau trên cơ sở hiểu biết, kĩ năng, kĩ xảo và kinh nghiệm cũng nhu sụ sã̃n sàng hành động [2].

Có nhiều tác giả coi năng lực là khả năng. Trong thực tế cho thấy năng lực được thể hiện dưới dạng tiềm ẩn, người ta gọi là khả năng, nhưng trong hoạt động năng lực bộc lộ dưới dạng kĩ năng hành động nên nếu coi năng lực là khả năng là chưa chuẩn xác.

Kế thừa các thành tựu nghiên cứu của các tác giả trong và ngoài nước, tác định nghĩa năng lực như sau: Năng lự là hành động của cá nhân được biểu hiện ơkiến thức, kĩ năng, thái độ phù hợp với yêu cầu của hoạt động đảm bảo cho hoạt động đạt kết quả cao với chi phí thấp nhất.

\subsubsection{Năng lục sáng tạo}

Nói về NLST các tác giả đưa ra một số ý kiến:

Huỳnh Văn Sơn cho rằng: "Năng lực sáng tạo là khả năng tạo ra những cái mới hoặc giải quyết vấn đề môt cách mói mé của con nguời” [6, tr.29].

Trần Việt Dũng: Năng lực sáng tạo là khả năng tạo ra cái mới có giá trị của cá nhân dựa trên tổ hợp các phẩm chất độc đáo của cá nhân đó. [3, tr.162]

Kế thừa các quan điểm trên chúng ta có thể nhận biết về năng lực sáng tạo (NLST) qua những dấu hiệu sau:

- Tính mới và độc đáo biểu hiện:

+ Đề xuất cách giải quyết mới ngắn gọn hơn đối với vấn đề quen thuộc.

+ Phát triển nhiều ý tưởng từ một vấn đề, đề xuất các phương pháp giải quyết.

+ Vận dụng cái đã có để tạo ra những cái mới mà vẫn đảm bảo yêu cầu và đạt kết quả tốt.

+ Đề xuất và thực hiện cách làm mới không theo đường mòn, không theo quy tắc đã có.

+ Tạo ra sản phẩm mới, ý tưởng mới, độc đáo.

- Dựa trên tổ hợp các phẩm chất độc đáo của cá nhân: có thể kể đến ba thành phần cơ bản trong NLST, đó là tư duy sáng tạo, động cơ sáng tạo và ý chí.

+ Tư duy sáng tạo: Là hệ thống những thao tác, cách thức của não bộ xử lí, biến đổi các dữ liệu, thông tin nhằm hình thành ý tưởng, lời giải của vấn đề sáng tạo.

+ Động cơ sáng tạo: Là cái thúc đẩy chủ thể thực hiện hoạt động sáng tạo.

+ Ý chí: Nếu động cơ thúc đẩy hành vi sáng tạo, tư duy đảm bảo hoạt động sáng tạo đưa ra lời giải của vấn đề thì ý chí sẽ giúp chủ thể vượt qua những khó khăn, cản trở trong quá trình sáng tạo nhằm đi tới đích. Sáng tạo đòi hỏi lòng kiên trì, can đảm, kiên định vượt qua những khó khăn, rào cản từ bản thân, điều kiện (thời gian, tài chính, phương tiện), định kiến xã hội và cả những thất bại tạm thời để hướng tới kết quả cuối cùng.

3. Mục tiêu, nội dung, phương pháp phát triển năng lụ̣c sáng tạo cho sinh viên sư phạm

\subsection{Mục tiêu}

Mục tiêu việc phát triển NLST cho sinh viên sư phạm là nhằm giúp sinh viên phát triển toàn diện trở thành những con người năng động, sáng tạo, chủ động trong mọi tình huống và có khả năng thích ứng cao đáp ứng nhu cầu phát triển kinh tế của đất nước, khu vực và quốc tế. Phát triển NLST cho sinh viên sư phạm cũng chính là phát triển nghề nghiệp cho sinh viên, giúp sinh viên sau khi tốt nghiệp đáp ứng yêu cầu của nghề nghiệp và thực hiện tốt chức năng, nhiệm vụ của người giáo viên.

Mục tiêu việc phát triển NLST cho sinh viên sư phạm làhướng tới ba mục tiêu cụ thể sau đây:

- Phát triểnhệ thống kiến thức NLST:Để phát triển NLST cho học sinh thì bản thân sinh viên sư phạm ngay từ khi ngồi trong ghế nhà trường họ cần được trang bị kiến thức NLST (Năng lực sáng tạo trong dạy học và giáo dục). Cụ thể đó là kiến thức của các lĩnh vực khoa học, hiểu biết bản chất của sự sáng tạo và những phẩm chất năng lực cần có của người sáng tạo.

- Phát triển hệ thống kĩ năng sáng tạo: Phát triển hệ thống kĩ năng sáng tạo cho sinh viên sư phạm tôi chú ý tới phát triển kĩ năng sáng tạo đặc thù của nghề dạy học đó là các kĩ năng sáng tạo trong dạy học và giáo dục. Điều này giúp sinh viên ra trường có thể thích ứng tốt với sự thay đổi và phát triển của nghề nghiệp.

- Phát triển hệ thống thái độ sáng tạo:Đảm bảo choquá trình hình thành và phát triển NLST đạt kết quả cao.

\subsection{Nội dung}

Nội dung phát triển NLST cho sinh viên sư phạm được thiết kế phù hợp với mục tiêu đặc thù sinh viên sư phạm nhằm phát huy tính tích cực, độc lập, sáng tạo của họ. Đồng thời, nó mang tính hệ thống, tính kế thừa sao cho kết quả giáo dục của giai đoạn trước làm cơ sở, tiền đề cho giai đoạn sau.

Nội dung phát triển NLST cho sinh viên sư phạm ngoài việc phát triển tư duy sáng tạo, động cơ sáng tạo, ý chí... thì nội dung phát triển NLST cho sinh viên sư phạm có đặc thù riêng trong bài viết này tác giả đề cập tới phát triển NLST trong quá trình dạy học và giáo dục.

- Phát triển NLST trong quá trình dạy học:

+ NLST phát triển chương trình;

+ NLST trong xây dựng và thực hiện kế hoạch dạy học;

+ NLSTđánh giá kết quả học tập của HS;

+ NLST giải quyết các vấn đề nảy sinh trong thực tiễn dạy học;

- NLST trong quá trình giáo dục: 
+ NLST trong tìm hiểu đối tượng và môi trường giáo dục;

+ NLST trong xây dựng và thực hiện kế hoạch GD;

+ NLST trong đánh giá kết quả giáo dục;

+ NLST trong tư vấn tham vấn cho HS.

\subsection{Phưong pháp}

Phát triển NLST cho sinh viên được thực hiện bằng nhiều phương pháp khác nhau cụ thể:

\section{* Phưong pháp làm việc nhóm}

Thực chất của phương pháp này giáo viên tổ chức cho SV tham gia trao đổi, giải quyết về một vấn đề hoặc nội dung theo nhóm, giảng viên kích thích SV tự giác, tích cực hợp tác để giải quyết nhiệm vụ đặt ra, trên cơ sở đó rút ra nhận xét, kết luận.

Phương pháp làm việc nhóm được chia ra làm hai loại: nhóm nhỏ và nhóm lớn. Nhóm nhỏ được sử dụng phổ biết trong quá trình dạy học đặc biệt trong phương thức đào tạo theo HTTC do phương pháp này nó đáp ứng rất tốt mục tiêu cải cánh - phát huy cao độ tính tích cực, sáng tạo trong học tập của SV. Làm việc nhóm còn là phương tiện học hỏi có tính chất dân chủ, mọi cá nhân được tự do bày tỏ quan điểm, tính sáng tạo, biết đón nhận quan điểm bất đồng, hình thành quan điểm cá nhân giúp $\mathrm{SV}$ rèn luyện kĩ năng sáng tạo, kĩ năng nói và biết lắng nghe người khác nói, kĩ năng giải quyết, kĩ năng hợp tác, kĩ năng phát biểu trước đám đông. Ngoài ra thảo luận theo nhóm còn giúp $\mathrm{SV}$ có kĩ năng tổ chức, quản lý, tự quản tạo điều kiện để các em tự trải nghiệm phát triển ý tưởng sáng tạo của mỗi cá nhân trong nhóm.

Đặc điểm của phương pháp làm việc nhóm:

+ Mang tính tích cực, tự lực, tự giác rất cao và có tính chất chủ thể.

+ Đòi hỏi người học phải có kiến thức, kinh nghiệm, có đủ tài liệu tham khảo.

+ Người học tìm ra kiến thức mới, nhìn vấn đề nhiều góc cạnh khác nhau.

+ Về mặt xã hội: Thảo luận tạo điều kiện phát triển quan hệ giữa các thành viên nhóm: nghe, nói, tranh luận, lãnh đạo.

+ Về mặt giáo dục: Phát triển tính dân chủ, hợp tác ở SV.

\section{Tổ chức cho SV làm việc nhóm}

Nhiệm vu của $G V$ : Lựa chọn và giao các nội dung, các vấn đề, công việc và các yêu cầu liên quan cho các nhóm SV thực hiện, nguồn tài liệu tham khảo tối thiểu...

Thiết kế kịch bản cho nội dung làm việc nhóm.

Tham dự, hướng dẫn, đạo diễn, nhận xét và tổng kết các sản phẩm của từng nhóm. GV cần khẳng định những nội dung đúng, sửa chữa những nội dung chưa đúng hoặc "chốt" nội dung của vấn đề, dùng nó như một phương tiện để chuyển tải nội dung cốt lõi của chủ đề thảo luận.
Đánh giá, cho điểm phần chuẩn bị trình bày, thảo luận của từng nhóm hoặc từng $\mathrm{SV}$ và tích lũy vào kết quả cuối của môn học.

Nhiệm vu của $S V$ : Nhận nhiệm vụ, thời hạn hoàn thành, mẫu báo cáo hoạt động theo nhóm.

Nhóm trưởng lên kết hoạch, phân công công việc cho các thành viên, thời gian hoàn thành, triển khai kết hoạch, xem xét kết quả đạt được so với mục tiêu đề ra.

Trình bày báo cáo theo phân công.

Theo dõi, bổ sung, góp ý bài trình bày của các bạn cùng lớp, hoàn chỉnh bài trình bày đó hoặc của mình.

Hỏi, đối thoại, tranh luận những vấn đề đã trình bày tại buổi thảo luận.

Tự nhận xét đánh giá bài thảo luận.

Theo dõi sự nhận xét, tổng kết của GV để hoàn chỉnh bài trình bày tại buổi thảo luận.

\section{* Phương pháp nêu vấn đề}

Phương pháp nêu vấn đề là GV tạo ra tình huống có vấn đề về một vấn đề, còn $\mathrm{SV}$ thì tự lực suy nghĩ, thảo luận, giải đáp dưới sự định hướng của GV. Quá trình suy nghĩ, thảo luận, giải đáp là điều kiện tốt để kích thích tính năng động sáng tạo, sự độc lập suy nghĩ, SV dần dần tiếp thu kinh nghiệm hoạt động sáng tạo hình thành phong cách học tập và làm việc mới làm cơ sở cho kĩ năng HĐXH phát triển.

Trong quá trình đó, $\mathrm{GV}$ vừa là người cung cấp thông tin, truyền đạt kiến thức (bằng cách nêu vấn đề) để SV lĩnh hội, vừa là người kích thích tự giác, tích cực suy nghĩ sáng tạo của SV trong học tập đồng thời tạo ra bầu không khí dân chủ giữa thầy và trò để đạt hiệu quả cao trong học tập.

\section{Tổ chức phương pháp nêu vấn đề}

GV xây dựng vấn đề, các câu hỏi chính cần nghiên cứu, các nguồn tài liệu tham khảo.

Tổ chức lớp học để nghiên cứu vấn đề: chia nhóm, giao vấn đề, thống nhất các qui định về thời gian, phân công, trình bày, đánh giá...

Các nhóm tổ chức nghiên cứu, thảo luận nhằm trả lời các câu hỏi của vấn đề thông qua đó giúp $\mathrm{SV}$ nắm tri thức ở trình độ vận dụng.

Tổ chức báo cáo và đánh giá: các nhóm trình bày kết quả nghiên cứu, giáo viên tổ chức đánh giá.

\section{* Phuơng pháp dư án}

Phương pháp dự án là phương pháp GV hướng dẫn SV thực hiện một nhiệm vụ học tập phức hợp, có mục tiêu rõ ràng, gắn với thực tiễn, kết hợp lí thuyết với thực hành. SV được hướng dẫn để thực hiện các công việc như tự lập kế hoạch, tự triển khai thực hiện kế hoạch, tự đánh giá kết quả. Hình thức làm việc chủ yếu là theo nhóm, kết quả của dự án là những sản phẩm cụ thể, được trình bày rõ ràng, có thể giới thiệu được. 
Phương pháp này lấy người học làm trung tâm, thông qua những nhiệm vụ mang tính mở, khuyến khích SV tìm tòi, hiện thực hoá những kiến thức đã học trong quá trình thực hiện và tạo ra những sản phẩm của chính mình. Phương pháp này giúp $\mathrm{SV}$ gắn lý thuyết với thực hành, tư duy và hành động, nhà trường và xã hội, từ đó phát triển NLST cho $\mathrm{SV}$.

Cách tiến hành:

Bước 1: Chọn một đề tài và xác định mục tiêu dự án: GV có thể định hướng một dự án hoặc để SV tự đề xuất một dự án.

Bước 2: Xây dựng đề cương kế hoạch thực hiện.

Bước 3: Thực hiện dự án: các thành viên thực hiện công việc theo kế hoạch đã đề ra cho nhóm và cá nhân.

Thu thập thông tin: từ sách báo, tạp chí, mạng internet, khảo sát, điều tra, phỏng vấn...

Xử lí thông tin: tổng hợp, phân tích dữ liệu (có thể biểu hiện bằng sơ đồ, biểu đồ...).

Thảo luận thường xuyên giữa các thành viên trong nhóm để giải quyết các vấn đề và kiểm tra tiến độ.

Xây dựng sản phẩm: tập hợp các kết quả thành một sản phẩm cuối cùng.

Bước 4:Giới thiệu sản phẩm trước tập thể lớp.

Trình bày, giới thiệu sản phẩm bằng các cách: Bài viết, Powerpoint, bản đồ, tranh ảnh, mô hình, kể cả việc đóng kịch, kể truyện...

Bước 5:Đánh giá kết quả đạt được so với mục tiêu xác định

SV tự rút ra những bài học từ việc học theo dự án: đã học được gì? Hình thành được những thái độ tích cực nào? Có hài lòng về kết quả thu được không? Đã gặp những khó khăn gì và đã giải quyết như thế nào? Những cảm nhận của cá nhân sau khi thực hiện xong một dự án?

GV: Đánh giá chất lượng sản phẩm giới thiệu, kết quả tự đánh giá, phương pháp làm việc.

\section{* Phuơng pháp tụ trải nghiệm}

Tự trải nghiệm dưới sự định hướng, tư vấn của $\mathrm{GV}$ sẽ giúp SV rèn luyện khả năng tự tin trước người khác, kĩ năng giải quyết vấn đề. Tự trải nghiệm của SV giữ vai trò rất quan trọng, nó là nhân tố quyết định tới việc nâng cao NLST của SV. Bên cạnh đó, tự trải nghiệm còn góp phần nâng cao hoạt động trí tuệ của $\mathrm{SV}$ trong việc tiếp thu và hiểu tri thức về sáng tạo, rèn luyện cho SV kĩ năng độc lập suy nghĩ, độc lập, sáng tạo trong giải quyết các vấn đề khó khăn trong quá trình học, giúp SV tự tin hơn trong cuộc sống của mình, thích ứng và bắt nhịp nhanh với những tình huống mới lạ mà cuộc sống hiện đại mang đến, kể cả những thách thức to lớn từ môi trường nghề nghiệp. Tự trải nghiệm của $\mathrm{SV}$ cần phải được tăng cường trong học tập trên lớp, trong thực hành thực tập chuyên môn, trong hoạt động giáo dục ngoài giờ lên lớp và tự rèn luyện của mỗi cá nhân SV.

\section{* Phuơng pháp đóng vai}

Đóng vai là phương pháp tổ chức cho SV thực hành, "làm thử" một số cách ứng xử nào đó trong một tình huống giả định. Đây là phương pháp nhằm giúp SV suy nghĩ sâu sắc về một vấn đề bằng cách tập trung vào một sự việc cụ thể mà các em vừa thực hiện hoặc quan sát được. Việc "diễn" không phải là phần chính của phương pháp này mà điều quan trọng là sự thảo luận sau phần diễn ấy.

Có thể tiến hành đóng vai theo các bước sau:

- Chuẩn bị:

+ GV chia nhóm, giao tình huống đóng vai cho từng nhóm và quy định rõ thời gian chuẩn bị, thời gian đóng vai.

+ Các nhóm thảo luận chuẩn bị đóng vai.

- Thực hành: Các nhóm lên đóng vai.

- Nhận xét, đánh giá.

* Phuơng pháp giao công việc

- Là phương pháp lôi cuốn SV vào các hoạt động đa dạng với những công việc cụ thể, với nghĩa vụ xã hội nhất định.

- Tác dụng của phương pháp giao việc là $\mathrm{SV}$ có cơ hội vận dụng những tri thức đã học của công việc cụ thể, với những yêu cầu nhất định. Nhờ đó $\mathrm{SV}$ được thể hiện những kinh nghiệm ứng xử trong các mối quan hệ đa dạng và hình thành được hành vi ứng xử phù hợp với những yêu cầu của công việc được giao.

- Khi giao việc cho SV cần chú ý:

+ Chọn công việc phù hợp với mục đích, yêu cầu giáo dục.

+ Công việc phải phù hợp với đặc điểm lứa tuổi SV.

+ Đưa ra những yêu cầu cụ thể, giúp họ có thể định hướng đúng đắn cho toàn bộ chuỗi hoạt động của họ nhằm thực hiện công việc được giao.

+ Phải tính đến hứng thú, năng khiếu của người được giáo dục nhằm phát huy được thế mạnh của họ trong hoạt động.

+ Để tập thể giao việc cho cá nhân với những yêu cầu rõ ràng nhằm tạo cơ hội cho SV phát huy ý thức, năng lực tự quản và tính tích cực đối với việc được giao.

+ Theo dõi và giúp đỡ để SV hoàn thành mọi yêu cầu của công việc được giao.

+ Kiểm tra, đánh giá công khai kết quả hoàn thành công việc của cá nhân, tập thể.

\section{* Phương pháp rèn luyện}

- Là phương pháp tổ chức cho SV được thể nghiệm ý thức, tình cảm của mình về các chuẩn mực xã hội trong các tình huống đa dạng của cuộc sống qua đó hình thành và củng cố được những hành vi phù hợp với các chuẩn mực xã hội đã được quy định.

\section{- Tác dụng:}

+ Tạo cơ hội cho người được giáo dục thâm nhập vào những tình huống đa dạng từ đơn giản đến phức tạp, từ dễ đến khó. 
+ Tạo cơ hội cho người được giáo dục biến kết quả tập luyện (hành vi) thành thói quen bền vững.

- Trong quá trình giáo dục có thể tạo cơ hội cho người được giáo dục rèn luyện trong các tình huống: Đời sống tập thể; Hoạt động học tập, lao động; Sinh hoạt hàng ngày ở nhà, ở trường, xã hội; Các hoạt động xã hội nói chung, hoạt động từ thiện...

- Để tạo điều kiện cho người được giáo dục rèn luyện tốt cần:

+ Tận dụng những tình huống tự nhiên, tạo ra những tình huống thích hợp.

+ Kết hợp chặt chẽ với tự kiểm tra.

+ Tổ chức rèn luyện liên tục, có hệ thống.

+ Kết hợp tổ chức rèn luyện với tự tổ chức rèn luyện.

4. Quy tình phát triển năng lực sáng tạo cho sinh viên sư phạm

Việc xây dựng quy trình phát triển năng lực sáng tạo cho SV sư phạm được xây dựng cụ thể thành các bước không chỉ đạt được mục tiêu đề ra mà còn giúp GV và $S V$ thực hiện một cách thuận lợi.

Quy trình phát triển năng lực sáng tạo cho sinh viên sư phạm bao gồm các bước sau:

Bước 1: Chuẩn bị cho việc phát triển năng lụcc sáng tạo

Đây là khâu rất quan trọng đảm bảo cho quá trình phát triển năng lực sáng tạo đi đúng hướng và đạt được kết quả cao.

Việc phát triển năng lực sáng tạo của sinh viên được thực hiện thông qua nhiều con đường thông qua quá trình dạy học vào giáo dục.

Để thực hiện có kết quả bước này thì cần phải chú ý những vấn đề sau:

- Tìm hiểu đối tượng về năng lực, thái độ, ý thức học tập, năng lực sáng tạo, hoàn cảnh vùng miền, lối sống, chuyên ngành... của $\mathrm{SV}$. Trên cơ sở đó $\mathrm{GV}$ sẽ xác định được mục tiêu, nhiệm vụ, xây dựng môi trường, có biện pháp tác động hợp lý.

- Phân tích chương trình, nội dung lựa chọn nội dung môn học chiếm ưu thế để tích hợp nội dung phát triển năng lực sáng tạo vào trong chương trình. Xây dựng và phát chương trình theo hướng phát triển phát triển năng lực sáng tạo.

+ Xác định cụ thể hệ thống các năng lực sư phạm cơ bản phù hợp với việc phát triển năng lực sáng tạo. Hệ thống năng lực đó cần được cụ thể hóa thành hệ thống những mục tiêu cần đạt được của các hành động tập luyện.

+ Thiết kế nhiệm vụ, kế hoạch tổ chức phát triển cho SV theo hướng tăng cường năng lực sáng tạo.

+ Xây dựng tiêu chí để đánh giá kết quả năng lực sáng tạo của $\mathrm{SV}$ một cách hợp lý trên cơ sở xác định các chuẩn đo các hoạt động, hành động thực hành, sao cho kết quả thu được, một mặt phản ánh đúng năng lực sư phạm và năng lực sáng tạo của $\mathrm{SV}$, mặt khác nó có tác dụng định hướng, điều khiển và điều chỉnh các hoạt động dạy học và giáo dục.

- Lựa chọn các phương pháp tích cực, chủ động, xây dựng những nhiệm vụ nhằm phát huy tích tích cực, chủ động, sáng tạo; phát huy năng lực tìm tòi khám phá trong việc lĩnh hội tri thức.

- Tạo môi trường học tập, giáo dục thân thiện, cởi mở nhằm bồi dưỡng hứng thú giúp cho quá trình lĩnh hội kiến thức của SV mang lại kết quả cao.

- Thường xuyên kiểm tra, đánh giá chỉ ra cho SV những ưu điểm, những hạn chế có biện pháp khắc phục.

- Hướng dẫn và đôn đốc SV chuẩn bị tốt những nhiệm vụ cho tổ chức hoạt động dạy học và giáo dục.

- Chuẩn bị củaSV:

+ Tìm hiểu và nghiên cứu kĩ các nội dụng, nhiệm vụ mà GV giao cho.

+ Xây dựng kế hoạch thực hiện nhiệm vụ.

+ Phân công nhiệm vụ cho các thành viên.

+ Thường xuyên trao đổi với $\mathrm{GV}$ để được hướng dẫn chuẩn bị tổ chức các hoạt động.

+ Chuẩn bị các điều kiện cần thiết như: cơ sở vật chất, trang thiết bị phục vụ cho tổ chức hoạt động; phối hợp với các lực lượng giáo dục khác cùng tham gia tổ chức.

Bước 2:Tổ chứcthục hiện việc phát triển năng lục sáng tạo

Việc tổ chức phát triển NLST được thực hiện bằng nhiều con đường khác nhau:

Thông qua dạy học: đòi hỏi GV phải sử dụng đa dạng các hình thức và phương pháp dạy học tích cực: dạy học dự án, dạy học tình huống, dạy học nêu vấn đề, dạy học hợp tác, dạy học bằng tìm tòi khám phá, thảo luận... để tạo môi trường phát triển NLST. Ngược lại nếu trong dạy học mà không áp dụng các phương pháp dạy học tích cực thì sẽ không phát triển NLST cho SV.

Thông qua các hoạt động giáo dục: Tạo điều kiện để SV được tham gia vào nhiều hoạt động giáo dục khác nhau như: hoạt động giáo dục ngoài giờ lên lớp; hoạt động của Đoàn, Hội SV; hoạt động trải nghiệm thực tế...là con đường có nhiều thuận lợi cho việc phát triển NLST cho SV. Các hoạt động này giúp SV đi vào cuộc sống thực tiễn đây là môi trường tốt rèn NLST trong giao tiếp, ứng xử và trong các mối quan hệ khác nhau. Hơn nữa SV phải vận dụng kiến thức để đàm phán, thương lượng để thuyết phục và huy động các nguồn lực tổ chức các hoạt động và giải quyết nhiều tình huống này sinh nên đây là con đường có nhiều thuận lợi trong phát triển NLST cho SV.

Trong quá trình tổ chức phát triển NLST cần chú ý những vấn đề sau: 
- Việc chuẩn bị tổ chức cho các hoạt động phải được thực hiện chu đáo phù hợp từng đối tượng, với đào tạo theo HCTC: từ việc xác định mục tiêu, nội dung, phương pháp, hình thức tổ chức các hoạt động cho đến việc phân công nhiệm vụ cho các thành viên, các nguồn lực và điều kiện cơ sở vật chất.

- Trong quá trình tổ chức rèn luyện $\mathrm{GV}$ giữ vai trò chủ đạo định hướng, dẫn dắt phát huy tính tích cực, chủ động, sáng tạo của $\mathrm{SV}$. Biến quá trình tổ chức rèn luyện thành quá trình tự tổ chức rèn luyện của $\mathrm{SV}$.

- Sau mỗi một hoạt động cần phải nhận xét, rút kinh nghiệm kịp thời nhằm điều chỉnh việc tổ chức rèn luyện ở những lần tiếp theo.

Bước 3: Kiểm tra, đánh giá kết quả phát triển năng lục sáng tạo

Phát triển NLST là một quá trình lâu dài. Vì thế, việc kiểm tra, đánh giá kịp thời có ý nghĩa rất quan trọng giúp GV, SV luôn giữ được mối "liên hệ ngược" để thấy được điểm mạnh, điểm yếu từ đó giúp có điều chỉnh phù hợp nhằm nâng cao kết quả phát triển NLST cho SV sư phạm.

Để kiểm tra đánh giá kết quả phát triển NLST cho SV sư phạm cần phải xây dựng thang đo và các tiêu chí cụ thể dựa vào mục tiêu đã xác định.

Phân tích kết quả đánh giá và đưa ra những nhận định về những ưu điểm và hạn chế cũng như những tồn tại yếu kém cần được sửa chữa, khắc phục từ đó đề ra biện pháp để cải thiện tình hình.

\section{Kết luận}

Quá trình đổi mới căn bản và toàn diện nền giáo dục theo hướng chuẩn hóa, hiện đại hóa và hội nhập quốc tế đòi hỏi sự nỗ lực của toàn xã hội. Trong đó, sinh viên sư phạm (đội ngũ nhà giáo tương lai) có vai trò hết sức quan trọng bởi họ chính là lực lượng kế tiếp đóng góp vào sự đổi mới này.
Quá trình phát triển năng lực sáng tạo cho sinh viên sư phạm được thực hiện bằng nhiều con đường khác nhau và thể hiện đặc thù riêng gắn liền với quá trình dạy học và quá trình giáo dục. Trong quá trình phát triển đó cần xác định rõ khái niệm năng lực sáng tạo, mục đích, nội dung, phương pháp và quy trình phát triển nhằm tạo điều kiện thuận lợi cho quá trình phát triển năng lực sáng tạo cho sinh viên sư phạm đạt kết quả cao.

\section{TÀI LIỆU THAM KHẢO}

1. Côvaliov A. G. (1971), Tâm lý học cá nhân, tập 2, Nxb Giáo dục, Hà Nội;

2. Bernd Meier, Nguyễn Văn Cường (2011),Co sở đổi mói phuoong pháp dạy học, Potsdam - Hà Nội;

3.Trần Việt Dũng (2013), Một số suy nghĩ về năng lục sáng tạo và phương huớng phát huy năng lực sáng tạo của con nguời Việt Nam hiện nay, số 49 (trang 160 - 169);

4. Đảng Cộng sản Việt Nam (2011), Văn kiện Đại hội Đại biểu toàn quốc lần thứ XI, Nxb Chính trị Quốc gia, Hà Nội;

5. Hà Mỹ Hạnh (2016), Phát triển năng lực hoạt động xã hội cho sinh viên su phạm khu vực miền núi phía bắc trong đào tạo theo học chế tín chì, Nxb Đại học Thái Nguyên;

6. Huỳnh Văn Sơn (2009), Tâm lí học sáng tạo, Nxb Giáo dục Việt Nam, Hà Nội;

7. Nguyễn Quang Uẩn (chủ biên) (2005), Tâm lí học đại curơng, Nxb Đại học Quốc gia Hà Nội;

8. Nguyễn Quang Uẩn, Trần Trọng Thuỷ (2009), Tâm lý học đại cuoong, Nxb Đại học Sư phạm;

9. Weiner, F.E (2011), comparative performance measurement in schools, Weinhei and Basejl: Beltz Verlag, pp. 17 - 31.

\section{Developing creative ability for pedagogical students}

\section{Ha My Hanh}

\section{Article info}

\section{Recieved:}

$17 / 3 / 2018$

Accepted:

10/9/2018

Keywords:

Development, ability, creativity, creative ability, pedagogical students.

\begin{abstract}
Teachers are the decisive factors for the quality of education and training. In order to improve the quality of education, it is necessary to improve the quality of the teaching staffs and the quality of training teaching staffs. Therefore, if students at colleges of education want to become creative teachers, the first things is that they must develop their creative abilities when they are students. The paper articleanalyses deeply some issues: the creative ability? Objectives, contents, methods of developing creative ability for pedagogical students; The process of developing creative ability for pedagogical students.
\end{abstract}

